\title{
Los países del Pacífico Sur y el mar territorial
}

\begin{abstract}
Sergio Teitelaoim V., abogado, profesor de Derecho Comercial y Tributario de la Escuela de Comercialización de la Universidad de Chile. Es autor del Manual de Legislación de Industrias Pesqueras (Editorial Juridica, 1964, Santiago de Chile), Chile $y$ la Soberanía en el Mar (Editorial Andrés Bello, 1966, Santiago de Chile), Las Fronteras Ideológicas, una Agresión sin Barreras,
\end{abstract}

El mar de hoy no es sólo el bello espectáculo de sus aguas azuladas, sino un inconmensurable emporio de riquezas que la ciencia, la técnica $y$ el esfuerzo del hombre se empeñan en conquistar a través de tres vías fundamentales: perforaciones petroleras, submarinos atómicos y la pesca, con todas las implicaciones que de ello derivan, en el orden económico, estratégico y jurídico.

Frente a esta nueva, permanente y renovada fuente, cuya flora y fauna provee de materias primas a la industria química y es un depósito de alimentos para la humanidad, los Estados evidencian una tendencia general a la extensión de sus derechos en el mar. "En este plano surgen las diferencias entre los grandes y pequeños países. Las potencias marítimas se han manifestado unidas en la defensa de la libertad en alta mar, manteniendo aguas territoriales restringidas; en cambio los Estados débiles buscan un acuerdo internacional para una definición ambiciosa de sus aguas territoriales"1.

Los países densamente poblados buscan en el mar fuentes alimenticias; en sus rutas, nuevas vías de transportes y garantías defensivas y posiciones estratégicas. En este decenio constatamos situaciones internacionales de alta tensión; ensayos nucleares en alta mar; el bloqueo a Cuba por el camino que eligió; el affaire del barco "Pueblo" acusado por. Pyonyang de introducirse en las aguas territoriales de Corea del Norte para realizar actividades hostiles, y en el plano pesque-

\footnotetext{
${ }^{1}$ Hubert Moineville: "Revue de Défense Nationale", junio-julio 1968, Paris.
} 
Sergio Teitelboim / Los países del Pacifico Sur y el mar territorial ro, reiteradas detenciones de barcos atuneros, principalmente norteamericanos y secundariamente japoneses, que han sido sorprendidos por Perú y Ecuador, pescando dentro de la zona de las 200 millas que los países latinoamericanos del Pacífico. Sur reclaman como zona sujeta a su soberanía y jurisdicción.

\section{FRonter AS DEL MAR}

Se ha planteado en numerosos encuentros internacionales y en las Conferencias de Ias Naciones Unidas sobre Derechos del Mar, celebradas en Ginebra desde febrero a abril de 1958, la delimitación. del mar territorial; al no obtenerse la mayoría de los dos tercios requeridos por los Reglamentos de la Conferencia, no hubo acuerdo para determinarlo. Estados Unidos, Canadá y otros paises aceptaban seis millas; $3^{8}$ países se pronunciaron por un mar territorial de 3 a is millas marinas. Es indiscutible que la norma general del límite de 3 millas marinas como principio de Derecho Internacional ha recibido un golpe de muerte, pero no es menos cierto que la posición partidaria de las 200 millas sólo cuenta con el apoyo de los propios interesados. En la actualidad la mayoría de los países piensa que la extensión del mar territorial debe alcanzar de seis a doce millas.

\section{EL MUNDO BAJO EL MAR}

En el fondo, las dificultades de delimitación del mar y las consiguientes situaciones conflictivas que derivan, son las resultantes de la lucha por el dominio y explotación económica del mar y de sus fondos oceánicos que cubren las tres cuartas partes. del planeta terrestre y cuyas profundidades, plenas de riquezas, han sido investigadas por proyectos tan fabulosos y exitosos como el Programa Textite que permitió en marzo-abril del año ig6g, a nueve acuanautas norteamericanos permanecer sesenta días en el fondo del océano con el fin de determinar si el ser.humano puede vivir $y$ ejecutar trabajos significativos por un período largo a relativamente poca profundidad ${ }^{2}$.

\footnotetext{
${ }^{2}$ Reproducción de "The New York Times" publicado por "El Mercurio" del 28 de abril de 1969
} 
E S T U D I O.S. I N T E R N.A C I O N A L E S

Pero con mucha anterioridad, en el orden jurídico y en el plano de utilizar y aprovechar las riquezas del fondo marino, el Presidente Harry Truman, el 28 de septiembre de 1945 , formuló dos Proclamaciones. Por la primera, la $\mathbb{N}^{\circ} 2.667$ declara: "que el gobierno de su país considera los recursos naturales del subsuelo y lecho marino de la Plataforma Continental bajo el mar libre, pero contiguo a la costa de los Estados Unidos, como pertenecientes a su país y sujeto a su jurisdicción y control". Por la segunda, la $\mathrm{N}^{0} 2.668$, se autoriza al Gobierno para dictar las medidas de conservación y protección de los recursos de la piscicultura de la alta mar adyacente a la costa de los Estados Unidos y se hace con ellas expresas referencias a los depósitos de minerales, petróleo y demás riquezas que encierra el lecho del mar y que conforme a esas proclamas incorpora a Estados Unidos una extensiôn de $1.942 .500 \mathrm{Km}^{2}$ de plataforma continental.

\section{LA PLATAFORMA GONTINENTAL EN EL PACÍFICO}

Posteriormente numerosos países costeros reivindicaron para sí la plataforma continental. La nomenclatura para la topografía submarina fue propuesta en congresos realizados en Wiesbaden. y en Whashington, en que se definió la plataforma continental como "el zócalo que bordea a los continentes a cuyo dominio pertenece y que se extiende con mayor o menor extensión o amplitud, según los casos, hasta unos 200 metros de profundidad".

Pero la batimetría del mar es muy diversa y mientras en el Océano Atlántico hay un declive suave de los fondos, con existencia de una plataforma continéntal, en ocasiones de enorme extensión, el Océano Pacífico está rodeado de grandes cadenas montañosas que se corresponden frecuentemente en las inmediaciones de la costa, con grandes profundidades. No hay prácticamente plataforma continental. P.or lo que respecta a la costa del Pacífico Sur y especialmente Sur Oriental, la profundidad de $200 \mathrm{~m}$ para el zócalo continental, es incompatible con la realidad de su relieve.

En las Conferencias del Mar de Ginebra en 1958, en la Convención Sobre Plataforma Continental, en su artículo $\mathrm{I}^{\circ}$, se definió como 
Sergio Teitelboim / Los países del Pacífico Sur y el mar territorial tal: a) El lecho del mar y el subsuelo de las zonas submarinas adyacentes a las costas, pero situadas fuera de la zona del mar territorial hasta una profundidad de $200 \mathrm{~m}$. o más allá de este límite hasta donde la profundidad de las aguas suprayacentes permite la explotación de los recursos naturales de dichas zonas: b) El lecho del mar y el subsuelo de las regiones submarinas análogas y a las costas de islas.

Este artículo crearía una posición difícil para los países de América bañados por el Océano Pacífico, como lo hemos expresado en párrafo precedente y como lo explica el autor Ommanney: "En derredor de Ios continentes y por debajo del nivel del mar existe un zócalo, dependiente del piso que forma una plataforma de anchura variable y cuyo borde está limitado por la profundidad aproximada de 180 metros. Ha recibido el nombre de plataforma continental $y$, en algunas regiones, tiene considerable anchura, sirviendo de zócalo a numerosas islas continentales. Esto sucede, por ejemplo, frente a la costa noroeste de Europa, desde donde se extiende hacia occidente a partir del cabo Finisterre en Inglaterra, por una distancia de $35^{\circ}$ kilómetros, incluyendo las Islas Británicas y todo el Mar del Norte. En otros lugares la plataforma continental casi no existe y la línea de la costa conduce casi verticalmente a las aguas profundas, como acontece frente a la costa jalonada por ingentes montañas del oeste de Sudamérica"s.

Chile, de ratificar la Convención Sobre Plataforma Continental de Ginebra, prácticamente se habría visto privado de ella, pero con anterioridad al reivindicar para sí la plataforma continental el 23 de junio de 1947, estableció la soberanía sobre su zócalo y sus riquezas, cualquiera que sea la profundidad en que ésta se encuentre y sobre los mares adyacentes a sus costas, en toda la extensión necesaria para reservar, proteger, conservar y aprovechar los recursos y riquezas naturales que sobre dichos mares $y$ en ellos y bajo ellos se encuentren, dentro del perímetro formado por la costa con una paralela matemática proyectada en el mar a 200 millas marinas de distancia de las costas chilenas, articulado que es coincidente con lo acordado por Chile, Perú y Ecuador en la Declaración de Santiago del 18 de agosto de $195^{2}$, sobre Zona Maritima.

\footnotetext{
3F. D. Ommanny: "El Océano".
} 
Dada la estructura del Océano Pacífico, con una estrecha plataforma costera, se delimitó su extensión sin consideración a su profundidad y ya indicaban en el año 1947, la intención de extender su mar territorial a 200 millas. En esta posición jugaron un papel determinante intereses económicos: las minas de carbón se adentran en territorio cubierto por las agiłas, pero el influjo determinante lo motivó la defensa de compañías pesqueras que reclamaron frente a la caza indiscriminada de la ballena en nuestros mares, con graves perjuicios que hoy son más notorios. La más importante empresa en la materia, la Indus y personeros representativos de esa actividad, especialmente los señores Julio Ruiz Bourgeois, Fernando Guarello y Fernando Maira, son los verdaderos autores de la iniciativa, que si bien es cierto, en aquel momento defendian intereses particulares, posteriormente se ha convertido en preservación de una riqueza básica, que en el caso de Chile tiene una incidencia secundaria; y lo primordial para el Perú que le ha significado un aporte del $27 \%$ de sus ingresos en divisas $y$ que la convierten en un mar privilegiado ya que "la prodigiosa riqueza de las aguas que se extienden frente a unos $3.000 \mathrm{Km}$ de la costa sudamericana de Chile y Perú se debe a la forma en que las corrientes hacen subir de las profundidades las nutrientes más apropiadas para la flora y la fauna marinas que prosperan en las capas superficiales de esas aguas, mejor tal vez que en ninguna otra parte del mundo".4 Y reiteramos fundamentalmente para Perú, que desde el año 1962 y en forma sostenida se ha convertido en la primera potencia pesquera del mundo.

Todo ello a pesar de la tenaz oposición de las flotas pesqueras foráneas, las que aprovechándose de la imposibilidad del control absoluto sobre las 200 millas de mar territorial, han burlado su jurisdicción con grave peligro para las especies, llegándose al extremo que las plantas balleneras de Quintay e Iquique, debieron cesar sus actividades por la verdadera extinción de este mamífero del mar, practicada por pesqueros norteamericanos y japoneses; $y$ es conocida la actitud del importantísimo armador Aristóteles Onassis, quien envió a incursionar a su flota ballenera al Pacífico Sur, siendo sorprendido dentro de la jurisdicción de sus 200 millas por la Armada peruana,

\footnotetext{
4"El Barco Pesquero" $N^{\circ}$ 5, oct.-nov. ıg68.
} 
Sergio Teilelboim / Los paises del Pacífico Sur y el mar territorial

la que consiguió apresar a algunos de ellos y aplicándoles, para obtener su libertad, una multa de 3.000 .000 de dólares.

\section{La DECLARACIÓN DE SANTIAGO}

En la Primera Conferencia para la explotación y conservación de las riquezas marítimas del Pacífico Sur, celebrada en Santiago del il al ig de agosto de 1952, Chíle, Perú y Ecuador proclamaron la soberanía y jurisdicción que a cada uno de ellos corresponde sobre el mar que baña las costas de sus respectivos países hasta una distancia mínima de 200 millas marinas desde las referidas costas y sobre el suelo y subsuelo que a ella corresponde.

Para Chile se traduce en un mar territorial de $16.600 .000 \mathrm{Km}^{2}$. En importantes áreas para Ecuador que tiene un litoral de 320 millas. Perú con 1.100 millas de costas, afirma su ascendente desarrollo pesquero, ya que hace 20 años capturaba 84.000 toneladas de pescados y en el periodo septiembre 1967 -mayo 1968 , las embarcaciones peruanas pescaron 9.817 .768 toneladas de anchovetas.

Es indiscutible que en su origen este Acuerdo perseguía la defensa de intereses pesqueros privados, pero en el devenir histórico se ha traducido en una pugna entre la penetración imperialista y la defensa de riquezas básicas, con todas sus consecuenciales implicancias políticas que derivan de los intereses económicos y de la orientación de los gobiernos. Podemos recordar la indiferencia con que actuó en esta materia la Junta Militar de Gobierno que rigió en Ecuador y que con motivo del grave incidente que ocurrió en mayo de 1963 , cuando dos embarcaciones norteamericanas dedicadas a la pesca del atún fueron sorprendidas y capturadas en el Archipiélago de las Galápagos, convino en un "Pacto Secreto" por el cual se rectificaba esta política y se permitía la pesca y caza en sus aguas territoriales, "Modus Vivendi" que denunció el diario "El Tiempo" de Quito del 18 de junio de 1965 y el propio Canciller de esa Junta, Sr. Valencia, y que entre otros motivos contribuyó al reemplazo de ese Gobierno. Gobiernos posteriores han ratificado la política de Ecuador en defensa de las 200 millas, hasta el extremo de haberla consagrado en su nueva Constitución.

5 "El Barco Pesquero" N 5 . 
E S T U D I O S I N T ER N A C I O N A L E S

Para el nuevo Gobierno del Perú, presidido por el General Velasco Alvarado, junto a medida tan fundamental como la nacionalización de la IPC, la defensa de la zona marítima de 200 millas ha sido una bandera importantísima.

\section{Texto de la declaración de santiago}

\section{Este Acuerdo de Chile, Perú y Ecuador establece:}

$1^{\circ}$. Los gobiernos tienen la obligación de asegurar a sus pueblos las necesarias condiciones de subsistencia y de procurarles los medios para su desarrollo económico.

$2^{\circ}$. En consecuencia, es su deber cuidar de la conservación $y$ protección de sus recursos naturales $y$ reglamentar el aprovechamiento de ellos a fin de obtener las mejores ventajas para sus respectivos países.

$3^{\circ}$. Por lo tanto, es también su deber impedir que una explotación de dichos bienes fuera del alcance de su jurisdicción, ponga en peligro la existencia, integridad y conservación de esas riquezas en perjuicio de los pueblos que, por su posición geográfica, poseen en sus mares fuentes insustituibles de subsistencia y' de recursos económicos que les son vitales.

Por las consideraciones expuestas, los gobiernos de Chile, Ecuador y Perú, decididos a conservar $y$ asegurar para sus pueblos respectivos las riquezas naturales de las zonas del mar que baña sus costas, formulan la siguiente declaración:

$1^{\circ}$. Los factores geológicos y biológicos que condicionan la existencia, conservación $y$ desarrollo de la fauna $y$ flora maritimas en las aguas que bañan las costas de los países declarantes, hacen que la antigua extensión del mar territorial y de la zona contigua sean insuficientes para conservación, desarrollo $y$ aprovechamiento de esas riquezas a que tienen derecho los países costeros.

$2^{\circ}$. Como consecuencia de estos hechos, los gobiernos de Chile, Ecuador y Perú proclaman como norma de su política internacional marítima, la soberanía y jurisdicción exclusivas que a cada uno de ellos corresponde sobre el mar que baña las coslas de sus respectivos paises, hasta una distancia minima de doscientas millas marinas desde las referidas costas.

$3^{\circ}$. La jurisdicción y soberanía exclusivas sobre las zonas maritimas indicadas incluyen también la soberania y jurisdicción exclusivas sobre el suelo $y$ subsuelo que a ella corresponde.

$4^{\circ}$. En el caso de territorio insular, la zona de doscientas millas marítimas se aplicará en todo el contorno de la isla o grupo de islas. Si una isla o grupo de islas pertenecientes a uno de los países declarantes estuviera a menos de doscientas millas marinas de la zona marítima de esta isla o grupo de islas quedará limitada por el paralelo del punto en que llega al mar la frontera terrestre de los Estados respectivos.

$5^{\circ}$. La presente declaración no significa desconocimiento de las necesarịas limilaciones al ejercicio de la soberanía y jurisdicción eslablecidas por el derecho internacional en favor del 
Sergio Teilelboim / Los paises del Pacífico Sur y el mar territorial paso inocente o inofensivo, a través de la zona señalada, para las naves de todas las naciones. $6^{\circ}$. Los gobiernos de Chile, Ecuador y Perú expresan su propósito de suscribir acuerdos o convenciones para la aplicación de los principios indicados en esta Declaración, en los cuales se establecerán normas generales destinadas a reglamentar, a proteger la caza y la pesca dentro de la zona marítima que les corresponde y a regular y a coordinar la explotación y aprovcihamiento de cualquier otro género de productos o riquezas naturales existentes en dichas aguas $y$ que sean de interés común.

Esta Declaración de Sanliago ha sido duramente criticada y considerada como una exageración. Algunos la consideran "ejemplo de chovinismo del mar", "es una exageración y no puede ser sustentada a través de ninguna consideración razonable", "reclamaciones unilaterales como éstas han llevado o llevarán a una crisis en las relaciones internacionales", y otros sostienen que la finalidad es obtener tributos del mar libre a expensas de la pesca extranjera legítima y que esa es la intención de los Estados reclamantes 5 .

Indudablemente la Declaración de Santiago establece un sistema de carácter particularísimo, que le resta aplicación universal, pero que no afecta intereses de paises vecinos $y$ que ha encontrado amplia acogida en otros países como Colombia, cuyo Congreso ha aprobado un proyecto de ley extendiendo su mar territorial a 200 millas y con anterioridad ya había adoptado igual posición la República Argentina, El Salvador y hay serios propósitos de convertirlo en norma legal en Brasil y paises centroamericanos*.

\section{¿Preservar las RiQuezas Marítimas?}

Se ha sostenido y con mucha insistencia que el verdadero sentido de la Declaración de Santiago fue establecer una zona contigua para efectos pesqueros, y así han opinado personas como el ex Embajador chileno Sergio Gutiérrez Olivos, quien escribe: "La Declaración de Chile, Ecuador y Perú sobre zona marítima de 200 millas no puede ser considerada, a nuestro modo de ver, como una nueva e innecesaria reclamación de estos países sobre

\footnotetext{
${ }^{6}$ Barry B. L. Auguste "The Continental Shelf The Practice and Policy of the Latin American States".

*N. de la R. Según una información cablegráfica, Brasil acaba de decretar una extensión de su zona pesquera a 200 millas, ignorándose aún si el decreto respectivo le asigna a tal ampliación el carácter de mar territorial con todas las características juridicas que ello implica (Véase El Mercurio, "Brasil extiende su Mar Territorial", p. 3, 28 de marzo de 1970).
} 
E S T U D I O S I N T E R N A C I O N A L E S

derechos en su plataforma submarina. Todo, en cambio, nos lleva a pensar que nos encontramos ante la proclamación de un mar contiguo para efectos pesqueros ${ }^{7}$. Concuerdan con esta opinión personas a quienes les cupo participar en la redacción de la Declaración de Santiago y que sostienen que su verdadero espíritu fue crear una zona de protección para la pesca, la caza y riquezas naturales existentes en la referida zona marítima.

En forma reiterada el periódico chileno "El Mercurio" ha opinado así en su página editorial. En síntesis ha dicho: "Los tres países firmantes se unieron en un común propósito de resguardar las riquezas y de reglamentar su explotación, afirmando, al propio tiempo, su derecho preferente a las que se encontraban en el mar frente a sus costas"

La interpretación que se da en círculos del Ministerio de Relaciones Exteriores de Chile, es la de zona de jurisdicción para protección pesquera.

Otros personeros estiman que su verdadero concepto es el de "mar territorial", ya que la determinación de su extensión es precisada por la legislación interna y que así lo dispuso Chile por Decreto $\mathrm{N}^{\circ} 43^{2} \mathrm{pu}-$ blicado en el Diario Oficial $N^{\circ} 23.004$ de 24 de noviembre de 1954 y refrendada por Dictamen de 10 de septiembre de 1957 de la Contraloria General de la República. Ecuador fijó su mar territorial por Decreto Legislativo de 6 de noviembre de 1954, ratificado por el Ejecutivo por Decreto Supremo de 7 de febrero de 1955. Perú por resolución suprema $\mathbb{N}^{\circ}$ I 70 de I I de abril de 1953 y más enfático al darle a las 200 millas el carácter jurídico de mar territorial.

Pero más allá de la disquisición si "es mar territorial". o "zona de derecho preferencial para efectos pesqueros", debemos tener presente que la concepción sobre el mar no es la misma que la del año i $95^{2}$. Se ha desencadenado la gran pugna por el dominio del fondo de los mares por las grandes potencias y desde los propios círculos de Gobierno se dice: "America Latina tiene plena conciencia del derecho soberano de cada país, de disponer libremente de sus recursos naturales, de que la Cooperación Económica no puede supeditarse a condiciones políticas o militares",

\footnotetext{
7.Mar Territorial y Derecho MIoderno".

828 de junio de 1969 .

${ }^{9}$ Documento $\mathrm{N}^{\circ} \mathrm{g} / \mathrm{M}$ Cecl.a $17.5 .6 \mathrm{~g}$, Viña del Mar.
} 
Sergio Teitelboim / Los países del Pacífico Sur y el mar territorial

La explotación de la riqueza ictiológica es fundamental para Perú, que en forma sostenida ha pasado a ser el primer país pesquero del mundo. En la temporada 67-68 ha pescado casi 10.000 .000 de toneladas métricas de anchoveta, en números redondos, la quinta parte del total de los peces capturados en todo el mundo ${ }^{10}$.

En Chile, la industria pesquera incipiente, se convierte en una interesante fuente productiva, pasando a situarse en ig62 en el i 2 lugar en la escala mundial y con serias vicisitudes en los años posteriores. En el año 1967 fue normal y en el año 1968 , que pesqueramente fue bueno, capturó 194.000 toneladas, lo que permitió el desarrollo correcto de este complejo industrial que es básico para la economía de las provincias del norte, que contaron con el apoyo decisivo de la CORFo, institución que comprometió inversiones por la suma de $E^{\circ} 7.160 .000$ y 280.000 dólares en el bienio $67^{-}$ $68^{11}$, y que plantea el problema que las disposiciones legales sobre el mar y sus proyectos sobre racionalización de su industria y comercialización, no pueden redundar sólo en beneficio del interés privado. Vemos que la defensa del mar se ha traducido en una política de derechos económicos y frente a la crítica que se trataría de "un chovinismo en el mar", debemos recordar que se ha convertido en un acuerdo solidario de todos los países del cono sur del Pacífico.

En este sentido un paso trascendente lo ha dado el Gobierno del Perú al promulgar el 24 de julio de 1969 la Ley General de Aguas $N^{\circ}$ I $7.75^{2}$ que estatiza todas las aguas en sus distintos estados físicos establecidos: "Las aguas, sin excepción alguna, son de propiedad del Estado y su dominio es inviolable. No hay propiedad privada de las aguas, ni derechos adquiridos sobre ellas", y declarándose que entre éstas se encuentran las 200 millas de mar territorial.

\section{AtunERos PRIVADOS CONTRA gOBIERNos}

A raiz de esta Declaración de Santiago de I952, se han presentado frecuentes conflictos entre Perú y Ecuador con barcos pesqueros norteamericanos y secundariamente, japoneses, los que desde el año ig54 se repiten con cierta frecuencia al sorprenderse flotillas pesqueras

\footnotetext{
10 "El Barco Pesquero" $\mathrm{N}^{\circ} 5$.

${ }^{11}$ CORFO - Bienio $67-68$.
} 
de atún pescando dentro del límite de las 200 millas. En 1969 han adquirido contornos más trascendentales frente a la decidida posición de la Junta de Gobierno peruana. La cañonera peruana "Sullanera" capturó a los atuneros norteamericanos "San Juan" y "Cape Ann" y el 20 de junio de 1969 Ecuador sorprendió y dejó en libertad sin aplicarles multas a seis atuneros norteamericanos $y^{\prime}$ a tres japoneses. Posteriormente, el 24 de julio de 1969 ; una cañonera peruana capturó al pesquero japonés "Zenko Maru 30 ", el que quedó 'en libertad previo pago de $6.34^{2}$ dólares por concepto de multa $y$ derecho de tonelaje, ya que en el momento de su detención llevaba en bodegas 268 toneladas de atún. Además, los propietarios de la nave abonaron $3 \cdot 7$ i 6 dólares por licencia $y$ matrícula para poder seguir pescando en aguas peruanas durante un período de cinco días.

Más que el monto de la suma percibida, ello importa el ejercicio por el Perú de su soberanía sobre las aguas que se extienden hasta 200 millas de sus costas, al exigir permiso, matrícula, derecho de tonelaje y facultad de imponer multa y su pago de esa suma por los propietarios del barco.

En estos incidentes que han pasado a ser de ordinaria ocurrencia, el Gobierno y el Congreso norteamericanos han actuado en defensa de los intereses privados de sus nacionales $y$ han pretendido imponer medidas coercitivas. Su Senado decidió el 7 de noviembre de 1963 , por 57 votos a favor y 29 en contra, prohibir toda ayuda exterior a cualquier nación que afirme su jurisdicción con propósitos de pesca sobre alta mar a una distancia de sus costas mayor a la reconocida por Estados Unidos. Enmienda que fue patrocinada por el senador Thomas $\mathrm{H}$. Kuchell, quien sostuvo que las naciones latinoaméricanas se han apoderado de pesqueros norteamericanos imponiéndoles multas y a veces arrestando a sus tripulantes. "El propósito de la enmienda - agregó- es poner bien en claro que no ayudaremos a aquellas naciones que violen la libertad de los mares".

Este medio de presión económica, que constituye un serio atentado contra la soberanía nacional, recibió el más unánime repudio de todos los países afectados, debiendo una comisión del Congreso norteamericano, con fecha de 5 de diciembre de 1963 , eliminar la enmienda, insistiéndose "que Estados Unidos sólo reconoce la jurisdicción marítima hasta 3 millas, pero que de mantenerse la prohibición del Senado, haría menos probable la negación en torno a la disputa de los derechos de pesca". 
Pero Estados Unidos no ha desistido en la defensa de los intereses pesqueros privados. El 14 de agosto de 1968 fue firmada por el Presidente L. B. Johnson una ley que autoriza el empleo de represalias contra todos aquellos países que capturen barcos pesqueros norteamericanos a una distancia mayor de doce millas de sus costas nacionales. Las represalias a emplearse consistirían en la reducción de la ayuda económica otorgada por los Estados Unidos en un monto igual a la multa aplicada a los barcos norteamericanos por los países que los capture.

Ante ello, la Armada del Perú emitió un comunicado a través del cual hace constar que, en defensa de la soberanía nacional, seguirá vigilando las costas peruanas sobre las 200 millas consideradas por su país como legítima extensión del mar territorial. Al mismo tiempo los diarios de Lima publicaron una serie de artículos al respecto, entre los cuales destaca un comentario de "La Prensa": "Los Estados Unidos pretenden intervenir con fuertes presiones de tipo económico a la hora de "ayudarnos" con préstamos en dólares y otras medidas similares para que no mantengamos la defensa de nuestras riquezas marítimas. El Perú no puede inclinarse ante esta presión descarada, porque con ello hipotecaría no sólo su independencia económica, sino la riqueza marina que entraña el territorio nacional".

"Además, al propio tiempo la Cancillería y la Cámara de Diputados de Ecuador, rechazaron enérgicamente la nueva política norteamericana a la que consideran como desafortunada, reaccionaria y "medida de coacción y agresión económica". Por medio de un comunicado, la Cámara de Diputados expresó la firme convicción de Ecuador de seguir defendiendo sus aguas territoriales en una extensión de 200 millas"'12.

\section{LA ENMIENDA PELLY, LA "HICKENLOOPER PESQUERA"}

En el curso del año 1969 , frente a las reiteradas incursiones de barcos pesqueros a las costas del Ecuador y Perú y al conflicto de este último país con la IPC, la situación ha adquirido contornos dramáticos y en el Senado norteamericano, el representante republicano Thomas M. Pelly

12“El Barco Pesquero" $N^{\circ}$ 6, nov.-diciembre. 1968 . 
E S T U D I O S I N T E R N A C I O N A L E S

dijo: "Si el Presidente no toma medidas por sí mismo, el Congreso iniciará el estudio de una legislación para obligarlo a proporcionar protección militar para los navíos en peligro de captura". O sea, la flota de guerra dedicada a defender intereses particulares. Este mismo senador es el autor de la enmienda aprobada en 1967 que lleva su nombre, por la cual: "El Presidente tiene que suspender la venta de armas a todo gobierno que aprese una embarcación norteamericana en la región que los Estados Unidos considere aguas internacionales, a menos que pueda alegar razones de seguridad para proceder asi"'.

Pero no sólo sus indicaciones se refieren a pertrechos militares. E1 25 de abril de ig 69 , anunció que está preparado un proyecto de ley que asestará "un devastador golpe económico al Perú, si ese país continúa con su presente política de pesca. Su iniciativa prohibiría la importación de pescado y sus derivados desde aquellos países que interfieren en las flotillas pesqueras norteamericanas en aguas que Estados Unidos considere como internacionales".

En análogo sentido se pronunció el representante demócrata Edward Garmatz, Presidente del Comité Camaral sobre Asuntos Pesqueros y' de Comercio Marino, y el senador republicano George Murphy, quien dijo: "...no podemos permitir este despreocupado tiro al blanco sobre nuestras naves desarmadas, ya ocurrió dos veces este año sin justificación alguna"13.

Frente a estas declaraciones, la reacción no tardó en venir. El Canciller peruano Edgardo Mercado Jarrín replicó el I 2 de junio de I 969 en Buenos Aires: "El Gobierno de los Estados Unidos debe comprender que no hay que confundir el interés general con el de una compañía. En esta distorsión está el enfriamiento ${ }^{14}$.

Ante esta coacción impuesta, se reunieron los Ministros de Relaciones Exteriores de los tres países signatarios de la Declaración de Santiago y el I 7 de junio de $\mathrm{g} 6 \mathrm{~g}$ emitieron en Lima un comunicado conjunto que dice:

$1^{\circ}$ Los gobernantes de Chile, Ecuador y Perú ven, con profunda preocupación, la aplicación por el Gobierno de los Estados Unidos de medidas coactivas que pretenden obligar a

${ }^{13}$ Cable uPI, "El Míercurio", 21 ,6.6g.

14 Cable UPI, "El Mercurio", 13.6 .69 . 
Sergio Teitelboim / Los paises del Pacífico Sur y el mar territorial

los países del sistema del Pacífico Sur a que declinen la posición juridica adoptada por ellos en virtud de la Declaración de Santiago de 1952 y evitar asi el ejercicio de la Jurisdicción exclusiva de cada uno de dichos países sobre una zona maritima de 200 millas adyacentes a sus costas.

$2^{\circ}$ Chile, Ecuador y Perú, firmemente resueltos a mantener el ejercicio del derecho exclusivo a la referida zona, en vista de la importancia que representa para su desarrollo. han creido conveniente transmitir al Gobierno de los Estados Lnidos su justificada inquietud por la existencia de aquellas mediclas".

En torno a esta materia, se ha creado conciencia tanto en la ciudadania como en los círculos gubernamentales latinoamericanos. A ello se debe que el Informe de Nelson Rockefeller estimó necesario proponer:

"El Poder Ejecutivo debiera tratar de obtener la suspensión o modificaciones de las enmiendas Pelly, Hickenlooper, Symington y Roess que afectan el otorgamiento de la asistencia, y que incluyen interrupciones de ella cuando los paises adquieren armas avanzadas, o se apoderan de barcos pesqueros de los Estados Unidos que están operando sin licencia, o expropian sin adecuada compensación".

Vemos que se recomienda sólo la suspensión o modificacıón y no la eliminación de estas medidas coercitivas.

Por otro lado, Rockefeller coloca en un mismo plano una política armamentista, como la adquisición de armas avanzadas, con las medidas de defensa de materias primas, como lo constituye el apresamiento de barcos pesqueros extranjeros sorprendidos operando ilegalmente en sus mares.

\section{Eil nacionalismo latino americano}

Hemos visto que la finalidad primordial de la extensión del mar territorial ha sido la de preservar las riquezas ictiológicas, un fin proteccionista de las riquezas nacionales. En América, frente a los cambios políticos $y$ económicos, a los avances tecnológicos, a sus organizaciones políticas, se ha abierto amplio cauce una línea en defensa de sus bienes nacionales, máxime cuando el frio análisis de sus cifras la muestra como una exportadora de capital. "En el período i $960-66$ el ingreso bruto total de recursos extranjeros ascendió en América Latina a 23.430 millones de dólares, pero en el mismo período América Latina remesó al exterior, para el objeto indicado más arriba, la suma de 23.646 millones de dólares. Es dẹcir, en ese 
período América Latina exportó capitales por un monto de 2 I 6 millones de dólares"1s.

Esta dependencia externa y las hondas diferencias e incluso abierta contradicción entre los países latinoamericanos y sus poderosos vecinos del norte es ya reconocida por columnistas de órganos de prensa como "El Mercurio": "Desde su inauguración en $18 \mathrm{~g} 1$, el sistema interamericano se ha apoyado en la presunción de que existe "una armonía natural" de intereses entre Estados Unidos y sus vecinos del Sur. Es cierto que con frecuencia este concepto ha sido usado para describir en forma eufemística la subordinación de los gobiernos latinoamericanos a los intereses del socio mayor" 16 .

Creemos que de esta conciencia colectiva ạmericana que se está formando de defender en forma solidaria sus riquezas básicas y su soberanía nacional, ha tenido su expresión práctica en la posición unida frente a la extensión del mar territorial, porque pese a las divergencias, si se ha proclamado "La Soberanía" sobre el mar territorial o si se trata sólo de "una zona de jurisdicción exclusiva", los tres países, y aunque el más afectado es Perú, felizmente han actuado solidariamente y seguramente en ello ha influido el apoyo que ha recibido en toda América, el ejemplo peruano al recuperar sus riquezas básicas, esbozándose el concepto de "Nacionalismo continental" al que el Canciller Edgardo Mercado Jarrín se refiere diciendo: "En América está surgiendo un nuevo nacionalismo latinoamericano y este hecho no significa que el dogma de la soberanía debe perder vigencia". $Y$ el Canciller chileno Gabriel Valdés ha dicho: "Este es un nuevo nacionalismo que no tiene nada que ver con las antiguas rencillas entre países. Es el resultado de un convencimiento que ha llegado por razones económicas, pero que ahora también afecta la parte política"17.

En el documento de CEClA: "América-Latina expresa por primera vez en forma solidaria y decidida su expectativa de que los países industrializados y en particular Estados Unidos consientan en reestructurar sus relaciones económicas con esta parte del mundo en los campos comercial, financiero $y$ tecnológico, siguiendo los planteamientos formulados por los países dèl

is Alberto Baltra: "América Latina y la $2^{2}$ UNCTAD", $\mathrm{N}^{\circ}{ }_{4}$ Revista Estudios Internacionales, ig6g, Santiago de Chile.

${ }^{16}$ Luciano Tomassini, "El Mercurio", 23.6.69, p.3.

17 "Ercilla", 25.6.69. 
Tercer Mundo en las reuniones celebradas, UNCTAD en Ginebra y Nueva Delhi".

Esta nueva expresión en boga: "Nacionalismo continental", es la toma de conciencia en los propios círculos gubernamentales latinoamericanos, que las relaciones con los Estados Unidos no pueden estar subordinadas a sus intereses y rol tutelar. Se ha creado plena conciencia que la explotación es consubstancial con el sistema capitalista $y$ en nuestra época asume la forma de una explotación de metrópoli a periferia en los países dependientes, lo que determina así, que la forma del conflicto entre ambas tome también el carácter de una lucha nacional en que participan sectores de la búrguesía, como ocurre en Perú en su conflicto con la IPC y como es el caso en estudio de las 200 millas, en que los más beneficiados son los grupos pesqueros $y$ que por considerarla una justa lucha nacional, reciben el apoyo de las restantes clases sociales. Marcos Kaplan en su estudio "Estado, dependencia externa y desarrollo en América Latina" sostiene: ". . ciertas coyunturas internacionales, independientes a veces de la voluntad de las metrópolis $y$ de sus élites de poder, pueden crear oportunidades $y$ posiciones que sean aprovechadas de diferentes maneras por las clases hegemónicas $y$ dominantes de los países periféricos para asumir una independencia relativa y un poder más o menos autónomo de decisión y para intentar modificaciones significativas en la orientación y la configuración de la economía, de la sociedad y la política"18.

La reunión tripartita de los países del cono sur del Pacífico con los Estados Unidos es el reflejo de esta nueva mentalidad, ya que la experiencia histórica está demostrando a América Latina que para hacer valer sus intereses frente a grandes potencias industriales debe acrecentar a través de un frente unido su poder negociador.

\section{LA CONFERENCIA CUATRIPARTITA DE BUENOS AIRES}

Dentro de las normas de esta nueva política, el reconocimiento de contradicciones entre las economías de los países latinoamericanos y la de los Estadcs Unidos, se reunieron en agosto de 1969 en Buenos Aires representantes de los países de la Declaración de Santiago con personeros norteamericanos con el fin de buscar una posible solución a este litigio, asegurando los gobiernos

${ }^{18}$ Esludios Internacionales, Año 2-N ${ }^{\circ}$ 2, julio-septiembre Ig68, Santiago, Chile. 
E S T U D I O S I N T ER N A G I O N A L E

de Chile, Perú y Ecuador que la jurisdicción exclusiva hasta las 200 millas para mar territorial no figuraría en el temario de la reunión, sino que se arbitrarian los medios para poner fin al apresamiento de los barcos norteamericanos que tratan de explotar los ricos bancos de atún existentes en esa región del Pacífico ${ }^{19}$.

Las conversaciones sostenidas entre los días $1^{\circ}$ y 19 de agosto de 1969 ( $)^{\circ}$ previa suspensión de la prohibición norteamericana de venta de armas a Perú ý Ecuador), sólo constituyeron un intercambio de puntos de vista sobre la comercialización de productos pesqueros, colaboración científica y técnica de los Institutos Nacionales de Perú y del peligro de operaciones de barcos-fábricas $y$ asimismo, la necesidad de concesiones arancelarias por parte de los Estados Unidos, de carácter no discriminatorio y no recíproco sobre productos de mar, ya que productos como el atún en latas están afectados a la tarifa del $23 \%$ a las importaciones que prevalece en los Estados Unidos, la que resulta prohibitiva. Al no lograrse mayores avances, se acordó suspender la Conferencia para reanudarla a fines del año I 969 , en la ciudad de Buenos Aires.

En el fondo el problema fundamental, el mar territorial de 200 millas, no entró en discusión. Perú, Ecuador y Chile sostuvieron con antelación que no era materia de la agenda; sin embargo, su sombra flotaba e incidia fundamentalmente en los temas de discusión. Al plantearse la solicitud de permiso y el pago de matrículas para pescar dentro de la zona de las 200 millas, los países ribereños consideraron que debían ser dirigidas al respectivo Estado por caer dentro de su jurisdicción. En cambio Estados Unidos proponía un Instituto Regional de Pesca, formado por representantes de Perú, Chile, Ecuador y Estados Unidos, que sería el organismo que estudiaria la conservación de las especies, las investigaciones oceonográficas y que otorgaría las matrículas, proposición que desde luego fue rechazada, por ser una forma elegante de crear el principio que los actos de jurisdicción sobre "el mar territorial" quedaba en manos de este Instituto.

La Cancillería peruana, con fecha 23 de agosto de ig69. finalizada la Conferencia, emitió un comunicado reafirmando su soberanía al decir: "La posición del Perú en esta Conferencia está enmarcada dentro del espíritu y la letra del Decreto Supremo $\mathrm{N}^{\circ} 78 \mathrm{I}$ del $1^{\circ}$ de agosto de ig47, que define nuestra zona de jurisdicción marítima $y$ de lo estipulado en la

${ }^{19}$ Cable UPI, "El Mercurio". 26.6 .69$. 
Sergio Teitelboim / Los países del Pacífico Sur y el mar territorial

Declaración de Santiago de 1952, y en los demás convenios internacionales sobre los que se asienta el sistema de la Conferencia del Pacífico Sur".

"Las declaraciones de Chile, Ecuador y Perú pusieron de manifiesto la necesidad de adoptar disposiciones que tengan en cuenta la diferente posición que como naciones en desarrollo corresponde de un lado a los países del Pacífico Sur y del otro a los Estados Unidos de América en la condición de gran potencia industrializada".

Creemos que la solución sólo se encontrará en un ámbito más amplio como es el de las Conferencias de Mar de las Naciones Unidas dándoles una solución única. Son varios los paises que han ampliado su mar territorial. Islandia está bregando por una tesis como la de los países del Cono Sur del Pacífico, e incluso pesqueros privados canadienses $y$ norteamericanos del Pacífico han estimado que la extensión del mar territorial debe ser de 60 a 80 millas, posición que ha sido rechazada de plano por sus gobiernos.

El problema deberá ser solucionado porque las perspectivas y futuro del mar y su explotación son inconmensurables. Casi el $20 \%$ del petróleo que se produce hoy en el mundo proviene de pozos submarinos. La industria del petróleo ha invertido unos 8.000 millones de dólares en la explotación de las riquezas submarinas y espera que la producción alcance a un valor de I6.000 millones para 1977 y a ello contribuye en forma notable el adelanto científico tecnológico. En 1953, el hombre tenía la capacidad técnica para perforar pozos a 21 metros, en 1969 podrá hacerlo a 457 metros. Estos pozos estaban a no más de $40 \mathrm{Km}$ de la costa en 1953 , ahora hay algunos a I6I $\mathrm{Km}^{20}$.

El "New York Times", en un informe publicado el 7 de agosto de 1967 , afirma que se ha encontrado una rica concentración de oro, plata, zinc $y$ cobre bajo el Mar Rojo a una profundidad de 7.000 pies. Un cálculo muy moderado estima el valor de los minerales de este yacimiento en aproximadamente 1.500 millones de dólares ${ }^{21}$.

Un equipo de geólogos japoneses informó haber descubierto en las aguas del Mar Meridional de la China un campo petrolero que podría ser uno de los diez más grandes del mundo, lo que significáría un importante auge para el Japón que tiene que importar casi todo el petróleo que consume ${ }^{22}$.

${ }^{20} \mathrm{~V}$ isión, 28.3.69.

21 Teodoro Alvarado G., "El Dominio del Mar", Guajaquil ig68.

22 "El Mercurio" 29.8.69, Reproducción de "The New York Times". 
El problema del mar es de una vastedad que escapa al acuerdo regional y requiere un Tratado universal. Hemos señalado algunas de las riquezas inexploradas y el avance en su conocimiento después de la Segunda Guerra Mundial. Con las exploraciones con batiscafos, equipos de inmersión submarina, hoy ya es posible explorar, vivir $y$ trabajar bajo el agua a profundidades, realizar desde la superficie una extensa gama de operaciones en el fondo. En síntesis, los estudios y las posibilidades económicas son inconmensurables y los intereses potenciales en juego son gigantescos.

Herbert Moinville sostiene: "Si es esencial recordar que el progreso técnico ha dado una importancia creciente al uso del mar, es igualmente ya un medio estratégico de una importancia decisiva permanente. En efecto, es en alta mar donde se estacionan los submarinos nucleares de disuasión que tienen ya algunos Estados' ${ }^{32}$.

Estados Unidos apresuró la revolución estratégica en el mar al perfeccionar el submarino "Polaris", ya que actualmente, de todas las embarcaciones lanzacohetes, la más eficiente y peligrosa es el submarino tipo "Polaris". Dotado de motor nuclear, puede mantenerse sumergido por períodos prolongados, es capaz de aproximarse sin ser detectado a cualquier objetivo y posee un armamento de proyectiles balísticos de alcance medio capaces de destruir cualquier objetivo. Cuando llevan cabezales nucleares esos misiles se convierten en un arma decisiva.

"El almirante norteamericano Hyman Rickover, creador de los "Polaris", ha declarado que la Unión Soviética tiene ya más submarinos que Estados Unidos y que pronto puede estar en situación de lograr la superioridad en los de tipo "Polaris". La flota sumergible norteamericana es de 143 unidades contra 375 de la Unión Soviética. Estados Unidos tiene 8I submarinos nucleares contra 65 de la Unión Soviética. En el rubro de los "Polaris", la Unión Soviética logrará la paridad en submarinos nucleares en I 970 y en sumergibles "Polaris" en 1973 o 1974" 24.

La preservación de su seguridad y de su libertad de acción para todos los Estados constituyen hoy en día una de las razones que imponen al Estado el

${ }^{23}$ Revue de Défense Nationale, junio-julio 68, Paris.

24"El Mercurio", 29.8.69, Santiago de Chile (Véase también Alain Joxe: iFin de la preponderancia estratégica norteamericana? Estudios Internacionales, $N^{\circ} 11$, octubrediciembre 1969, N. de la R.). 
Sergio Teitelboim / Los países del Pacifico Sur y el mar territorial

cuidado de tener el mejor control posible de las extensiones marítimas que lo circundan.

En este orden de seguridad y acuerdo internacional, se celebraron bajo el auspicio de las Naciones Unidas las Conferencias Especializadas sobre el derecho del mar, celebradas en Ginebra en I958 y 1960, aprobándose Cuatro Convenciones y un Protocolo de firma facultativa sobre el mar territorial y zona contigua, acerca de las normas referentes al alta mar, sobre la pesca y conservación de los recursos vivos de alta mar y una relativa a la plataforma continental. La finalidad fundamental de estas Conferencias no fueron logradas al no obtenerse los dos tercios requeridos por los Reglamentos de la Conferencia para la determinación de la anchura del mar territorial y los límites de la pesquería.

Frente al mar y a su fondo oceánıco, ha surgido la pregunta: ¿. De quién es el mar? ¿Es de todos? ¿Puede ser del dominio de una nación en particular? Las Naciones Unidas reconocen que: "Ia gran mayoría de los países no está, por razones técnicas, financieras y de otro tipo, en posición de participar en la explotación de esos recursos" y afirma que el fracaso de los intentos para. conseguir un acuerdo mundial "que regule la exploración y explotación de esos recursos marinos" podía conducir "a una nueva forma de apropiacion colonialista".

Las Naciones Unidas, preocupada por el problema del mar, ha formado un Comité de Expertos y su Oficina de Asuntos.Jurídicos ha estudiado la materia $y$ en estos momentos fundamentalmente propone reservar para fines pacíficos los fondos marinos y oceánicos y de su subsuelo en alta mar, fuera de los límites de jurisdicción nacional actual y el empleo de sus recursos en beneficio de la humanịdad, ya que estima que de no hacerlo entrará en juego el dominio militar del fondo oceánico y su posterior explotación económica. Por ello, el 10 de marzo de 1969 , una Comisión permanente de 42 miembros de las Naciones Unidas comenzó a sesionar con el propósito de lograr un acuerdo internacional sobre la materia.

\section{UN FONDO SUBMARINO LIBRE DE ARMAS NUCLEARES}

En este sentido ya el delegado de Malta Sur, Sr. Andiv Pardo, en I966, en la Asamblea General de las Naciones Unidas, propuso: 
E S T U D I O S I N T ER N A G I O N A L E S

I) que el lecho del mar y el fondo oceánico que están por debajo de los mares que se encuentran más allá de la jurisdicción nacional no están sujetos a la apropiación en ninguna forma;

2) que el lecho del mar y el fondo oceanico que no estén comprendidos en los límites de la jurisdicción nacional se usarán exclusivamente para propósitos cientificos;

3) la exploración y la explotación del lecho del mar y del fondo oceanico, más allá de los límites de la jurisdicción nacional, se harán de una manera congruente con los principios de la Carta de las Naciones Unidas.

Pasos positivos se han dado al respecto, al comunicar el i 8 de marzo de I969, el Presidente norteamericano Richard Nixon y el Primer Ministro Soviético, Alexei Kosygin, a la Conferencia de Desarme de Ginebra, negociaciones para un tratado internacional que prohibirá el emplazamiento de armas nucleares en el lecho de los océanos, constituyendo una ampliación del acuerdo contra la proliferación de armas nucleares, negociado en 1968 en la Conferencia de.Ginebra, y complementado los tratados existentes prohibiendo la utilización de tales armas en el espacio exterior y en la Antártida.

Esta proposición, sin embargo, ha sido en su contenido mismo, controvertida. Los soviéticos presentaron un proyecto cuyo principal artículo dice: "El uso, para todo propósito militar del fondo y del lecho del mar y su subsuelo, más allá de las doce millas de zona marítima de los Estados costeros, será prohibido". Agregando el jefe de la Delegación, Sr. Alexei A. Roshkin, que el nuevo proyecto se àplicará a todas las armas, no sólo a las nucleares ${ }^{25}$.

El delegado norteamericano Sr. Gerard C. Smith declaró que no podía ser éste el sentido, diciendo: "Me inclino a dudar que nosotros tengamos interés en un tratado que prohibe todo empleo militar del fondo del mar, restringiéndolo sólo a "armas nucleares y de destrucción en masa", rechazando en consecuencia la completa desmilitarización del lecho oceánico.

Es sabido que en el plano internacional, los acuerdos no prosperan de inmediato y son sometidas a largas discusiones, pero vemos que se ha avanzado positivamente y que deberá pasar al desván la sentencia de Richelieu: "La nar es de todos los patrimonios, aquel sobre los cuales los

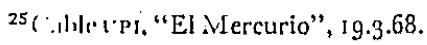


Sergio Teitelboim / Los paises del Pacífico Sur y el mar territorial derechos son menos claros. El verdadero título de su dominio es la fuerza y no la razón"'26.

Hoy que surge la nueva profesión de los "acuanautas", en la hora en que nueve personas han vivido por varios meses en el fondo del océano en el "Sealab", debe surgir el acuerdo mundial sobre la delimitación del mar territorial, de la plataforma continental, del fondo del mar, de su utilización con fines benéficos para la humanidad, reconociéndose los particularismos en beneficio de las naciones pequeñas, que no pueden estar, por razones técnicas, financieras, estratégicas, en igualdad de condiciones con las grandes potencias.

${ }^{26}$ Citado por Herbert Míneville: "Revue de Défense Nationale", junio’julio tg68. 